Portland State University

PDXScholar

\title{
A Study of Early Career Teachers' Practices Related to Language and Language Diversity During Mathematics Instruction
}

\author{
Erin Turner \\ University of Arizona \\ Amy Roth McDuffie \\ Washington State University \\ Amanda Sugimoto \\ Portland State University, asugimo2@pdx.edu \\ Julia Aguirre \\ University of Washington Tacoma \\ Tonya Gau Bartell \\ Michigan State University

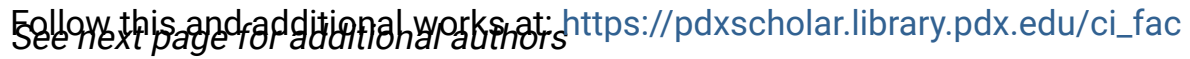 \\ Part of the Curriculum and Instruction Commons \\ Let us know how access to this document benefits you.
}

\section{Citation Details}

Turner, E., Roth McDuffie, A., Sugimoto, A., Aguirre, J., Bartell, T. G., Drake, C., ... Witters, A. (2019). A study of early career teachers' practices related to language and language diversity during mathematics instruction. Mathematical Thinking \& Learning, 21(1), 1-27.

This Post-Print is brought to you for free and open access. It has been accepted for inclusion in Curriculum and Instruction Faculty Publications and Presentations by an authorized administrator of PDXScholar. Please contact us if we can make this document more accessible: pdxscholar@pdx.edu. 


\section{Authors}

Erin Turner, Amy Roth McDuffie, Amanda Sugimoto, Julia Aguirre, Tonya Gau Bartell, Corey Drake, Mary Foote, Kathleen Stoehr, and Angela Witters 


\title{
A Study of Early Career Teachers' Practices Related to Language and Language Diversity during Mathematics Instruction
}

\begin{abstract}
The role of language in mathematics teaching and learning is increasingly highlighted by standards and reform movements in the US. However, little is known about teachers', and especially early career teachers' (ECTs) practices and understandings related to language in mathematics instruction. This multiple case study explored the language-related understandings and practices of six ECTs in diverse elementary classrooms. Using iterative cycles of analysis, we found that all ECTs regularly attended to students' mathematical vocabulary use and development. Yet, there was variability in ECTs' focus on how to teach mathematical vocabulary, expectations for students' precise use of mathematical terminology, and the use of multiple languages during instruction. These findings indicate that ECTs need more targeted support during teacher preparation and early career teaching in order to better support all students' language development in the mathematics classroom.
\end{abstract}

\section{Rationale}

In recent years, a range of mathematics education reforms and standards initiatives in the United States and internationally have drawn increasing attention to the role of language in teaching and learning mathematics (National Council of Teachers of Mathematics (NCTM), 2010, 2014; National Governor's Association Center for Best Practices \& Council of Chief School Officers (NGACBP \& CCSO), 2010; Adler, 2002; Parveva et al., 2011). Students are expected to use language in various ways in mathematics classrooms; for example, unpacking problem statements that include complex phrases, explaining and justifying thinking, and discussing connections between multiple representations (e.g., objects, drawings, diagrams) (Moschkovich, 2012; NGACBP \& CCSSO, 2010). In the U.S., the Common Core Standards for School Mathematics 
(CCSSM) have increased language expectations for all students with the emphasis on explaining reasoning over performing procedures. For example, Mathematical Practice 3, Construct viable arguments and critique others' reasoning, requires students to communicate mathematical justifications, and respond to others' ideas. Mathematical Practice 6, Attend to precision, requires that students "communicate precisely to others,... use clear definitions in discussions with others and in their own reasoning" (NGACBP \& CCSSO, 2010, p.7). These standards align with current research on language and mathematics that has found that children's language skills have a complex and intertwined relationship with their developing mathematical skills (Bernardo, 1999; Clarkson, 2007; Martinello \& Wolf, 2012; Purpura \& Ganley, 2014), and thus are relevant beyond the U.S. This emphasis on language has also expanded expectations for teachers, as they must attend to students' mathematical communication skills as well as conceptual understanding (Gutierrez, 2002; Santos, Darling-Hammond, Cheuk, 2012). This can be challenging, particularly in linguistically diverse classrooms where students may receive instruction in a language other than their home languages (Moschkovich, 2012). Given the increasing linguistic diversity among students in the United States (National Center for Education Statistics, 2014), and internationally (Parveva et al, 2011), attention to language practices in mathematics classrooms is critical (Chval, Pinnow, \& Thomas, 2015; Setati, 2012). Students not proficient in the language of instruction (i.e., language learners ${ }^{1}$ such as English learners in English-only instructional environments) may participate only marginally in group discussions of mathematical ideas and may struggle to make sense of language-intensive tasks (Abedi \& Herman, 2010; Secada \& de la Cruz, 1996). International studies in countries such as Spain (Gorgorio, Planas \& Vilella, 2002) and South Africa (Adler, 1997, 1998, 1999) have documented similar results. While we firmly uphold that all

\footnotetext{
${ }^{1}$ We use language learners to refer to students who are learning the language of instruction, which may differ from the language(s) spoken at home. Most often, we use this term to refer to English learners who receive schoolinstruction in English. In mathematics classrooms, all students are language learners as they are learning the terminology and ways of talking of the discipline. Our use of language learners is inclusive of these varied meanings.
} 
students, including language learners, can use language to communicate and make sense of ideas (Moschkovich, 1999; Turner, Dominguez, Maldonado \& Empson, 2013), the fact that students do not always have these opportunities suggests the need for more attention to effective instructional practices.

\section{Theoretical Perspectives}

In this section, we first outline key perspectives that informed our work, including what each perspective emphasizes in terms of teaching practices. Next, we discuss teachers' practices related to language and language learners in mathematics instruction, with a specific focus on the teaching dilemmas that arise.

\section{Perspectives Related to Language in Teaching and Learning Mathematics}

Researchers have conceptualized the role of language in mathematics instruction broadly in three ways: the lexicon perspective, the register perspective, and the situated-sociocultural perspective (Moschkovich, 2002). It is important to note that we view these three perspectives as nested, in that initial perspectives (e.g., lexicon) are included in subsequent perspectives (e.g., register).

Lexicon perspective. The lexicon perspective focuses on vocabulary acquisition (Dale \& Cuevas, 1987; Rubenstein, 1996), emphasizing the importance of learning mathematical language and vocabulary for successful decoding and solving of mathematics tasks, such as word problems (Mestre, 1988; Spanos, Rhodes, Dale, \& Crandall, 1988). Studies have documented relationships between students' language proficiency, and success solving word problems in that language, both in the US (Mestre, 1988) and internationally (Adetula, 1989, in Nigeria), though these relationships are complex and reflect various contextual factors. In classroom practice, scholars recommend that teachers explicitly teach mathematical vocabulary and how to translate from mathematical language to symbols (Baker et al., 2014; Dale \& Cuevas, 1987; Rubenstein, 1996). Students' potential 
confusion over mathematical vocabulary has been well documented, and explicit teaching of vocabulary (e.g., defining formal mathematical terms) is seen as successful intervention, particularly for language learners (IES, 2014; Miller, 1993). However, teachers have reported limited knowledge of instructional strategies for teaching mathematical vocabulary (IES, 2014). Moreover, scholars criticize the lexicon perspective as overlooking challenges that might arise due to linguistic and grammatical complexity (Martinello \& Wolf, 2012), or to the multiple meanings of words across contexts (e.g., Moschovich, 2002).

Register perspective. The register perspective addresses this critique by focusing on the multiple meanings of words in everyday life and mathematics (Farrugia, 2013, 2015; Schleppergrell, 2007), while still including important ideas from the lexicon perspective (i.e., the importance of learning mathematical vocabulary). The mathematics register includes vocabulary as well as "modes of argument, and mathematical practices" (Moschovich, 2012, p. 22). Scholars recommend that teachers intentionally unpack the multiple linguistic modes needed to understand and communicate using the mathematical register (i.e., symbols, oral language, written language, visuals such as graphs) (Schleppergrell, 2007). This is challenging because teachers may not be aware of the complex grammatical structures involved or how students could misinterpret such structures (O'Halloran, 2003). For example, the problem "Tina has twice as much money as George" does not mean that "George has twice as less [money] than Tina," but students unfamiliar with the nuances of the mathematical register may assume both statements are true (Schleppergrell, 2007, p. 143). Teacher moves that can support language learners as they navigate both mathematical and everyday registers include: (a) intentionally moving between registers (Lemke, 2003), (b) attending to unfamiliar mathematical and everyday words to alleviate student confusion (Lager, 2006), (c) creating problems based on students' experiences (Secada \& De La Cruz, 1996), (d) rewording tasks to use familiar language (i.e., cognates (Hernandez, 1999), or less complex 
language (Abedi \& Lord, 2001; Bernardo, 1999); and (e) using mathematical terms clearly and consistently and requiring students to do the same (Khisty \& Viego, 1999). These suggestions reflect findings from research in the United States (e.g., Khisty \& Viego, 1999; Secada \& De La Cruz, 1996) and internationally (e.g., Bernardo's (1999) study in the Phillipines). A critique of the register perspective is that it focuses on challenges related to multiple registers (Schleppergrell, 2007), instead of how students use multiple registers (and even multiple languages) to communicate.

Situated-sociocultural perspective. In response, the situated-sociocultural perspective focuses on how students use everyday and mathematical discourses simultaneously to communicate and construct meaning in order to participate in mathematical practices (Turner, Dominguez, Empson \& Maldonado, 2013; Moschkovich, 2002), while still including aspects of the prior perspectives. In describing the situated-sociocultural perspective, Moschkovich (2002) focused on how bilingual mathematics learners participate in mathematical Discourse communities (Gee, 1999) to develop mathematical and linguistic understanding. International research in various countries including the United Kingdom (e.g., Barwell, 2003, 2005), the United States (e.g., Dominguez, 2011), Spain (Planas, 2014), and South Africa (Setati, 1998, 2005), has contributed to this perspective by documenting the range of resources that students draw upon to engage in mathematical discourse, including gestures, code switching, everyday experiences, and linguistic structures. Teacher moves that can facilitate students' participation in mathematical discussions include explicitly asking students to listen and respond to each other's ideas, prompting students to clarify their statements, using visuals to support student understanding, and revoicing student ideas (Moschkovich, 1999; Turner et al., 2013a, 2013b). Moschkovich (1999) cautioned that teachers should focus on the meaning of students' contributions, not the form of the language itself (i.e., the grammatical accuracy). 
More recently, Moschkovich (2015) applied the situated-sociocultural framework to unpack "academic literacy" in mathematics. Academic literacy in mathematics involves discursive practices essential for participation in mathematics communities, including "mathematical proficiency, multiple symbol systems, and multiple modes of communication" (Moschkovich, 2015, p. 44). She argued that in light of this definition of academic literacy, language learners need opportunities to develop their mathematical proficiency in multiple ways. Specifically, their learning is supported by instruction that focuses on mathematical meaning as "situated, negotiated, and grounded in activity" (p. 59), rather than focusing on acquiring "the static meaning of words supplied by the teacher or a textbook" (pg. 59). Moreover, students' participation in mathematical discourse needs to be scaffolded to allow students to communicate in a variety of ways (e.g., gestures, drawings), while treating students' language as a resource not a deficit (Barwell, 2012; Moschkovich, 1999, 2002, 2012; Setati, 2012). This is true for all students, and in particular language learners.

\section{Teachers' Beliefs and Practices Related to Language in the Mathematics Classroom}

Research has outlined various strategies that support language learners' mathematical and linguistic development (e.g., Khisty \& Chval, 2002, Ross, 2014; and summarized in the sections above). However, teaching mathematics in linguistically diverse settings can be challenging, as noted by researchers in the United States, and internationally (Adler, 1998, 1999, 2002; Setati, 2005). Moreover, what teachers actually do in these settings can vary (Kayi-Aydar, 2015). In the sections that follow, we first introduce the notion of teaching dilemmas as a way we frame teachers' work in this study, and then highlight dilemmas that teachers navigate in their work with language and language learners in the mathematics classroom.

Teaching dilemmas. Throughout their careers, teachers face challenges related to their practice, and the construct of teaching dilemmas provides a lens for exploring how teachers negotiate these challenges (Lampert, 1985). Lampert (1985) argued that when teachers are faced 
with in-the-moment instructional decisions (e.g., Should I do this, or that?), they often do not draw upon theory to guide their decision-making, but on personal goals and their practical knowledge of the unique context within which they are teaching. This raises questions about how the perspectives about language in mathematics summarized above actually unfold and influence teachers' classroom practice. Building upon Lampert's work, Adler (2002) used the framing of teaching dilemmas to "capture and open up teachers' knowledge of the elusive, complex and dialectical nature of teaching and learning mathematics in multilingual classrooms" (p. 50). Adler found that teachers in multilingual mathematics classrooms in South Africa navigate ongoing dilemmas related to language, even if teachers do not explicitly frame them as such. In the sections that follow, we describe dilemmas related to balancing students' linguistic and mathematical development, student meaning making, and the use of multiple languages in the mathematics classroom.

Dilemmas related to language versus content. Adler $(1998,2002)$ noted that mathematics teachers often face dilemmas related to when to: a) make "mathematical language visible" so that students can learn the language, or b) allow language to be "invisible so that students can use the language to learn mathematics" (2002, pg.115). Adler referred to this challenge as the dilemma of transparency. Teachers in Adler's study reflected on instances in their teaching (i.e., dilemmas) when they wanted to draw attention to mathematical language, but at the same time teachers were hesitant to interrupt students' reasoning. Other researchers documented similar tensions, both among mathematics teachers and teachers of other content areas. For example, Creese (2005) found that some mathematics teachers view language and explicit language instruction as less important than content-focused teaching. In fact, in some instances teachers' belief that they are a content teacher and not a language teacher contributed to a limited focus on students' language development (Creese, 2005; Tan, 2011), reflecting a particular response to Adler's dilemma of transparency. Moreover, Tan (2011) found that when content teachers focused on language, they 
prioritized the acquisition of vocabulary words, in alignment with a lexicon perspective, over linguistic forms and registers. Tan (2011) argued that testing and curricular pressures, a lack of collaboration between content and language teachers, and a lack of professional development for content teachers all contributed to teachers' focusing on content-specific vocabulary over linguistic forms and functions.

Dilemmas related to meaning making and discussion. In this second dilemma, Adler (2002) contended that in inquiry-based mathematics classrooms, teachers navigated their desire to validate and be inclusive of "diverse learners' meanings", versus "developing [students] mathematical communicative competence," so that students move towards key mathematical understandings through discussions (p. 113). In this dilemma of mediation, teachers struggled to reconcile these twin goals as they scaffolded language learners' participation in mathematical discourse. For example, during discussions students frequently used imprecise mathematical language and evidenced emerging discourse skills and mathematical understandings. Therefore, teachers negotiated a dilemma related to introducing more formal mathematical language and ideas without detracting from an inquiry-based instructional practice focused on students' developing their own understandings (Adler, 2002). Other studies have documented similar tensions. For example, students not proficient in the language of instruction may struggle to make sense of language-intensive tasks, and may participate only marginally in group discussions of mathematical ideas (Abedi \& Herman, 2010; Secada \& de la Cruz, 1996). To support students, Hufferd-Ackles, Fuson, and Gamoran Sherin (2004) argued that teachers must develop a "math-talk learning community" where students develop discourse practices necessary to explain and justify their mathematical thinking as well as question and explore the thinking of their peers. This is a complex practice because teachers must balance directly modeling these discourse practices with more 
inquiry driven instructional practices that focus on eliciting and developing students' diverse understandings (Adler, 2002; Forman, Larreamendy-Joerns, Stein, \& Brown, 1998).

Dilemmas related to multiple languages. How teachers navigate the multiple languages that students bring into the mathematics classroom matters, as it has the potential to shape students learning experiences (Janzen, 2008). For monolingual teachers in multilingual classrooms, or for multilingual teachers who do not share the home language of their students, this can be challenging because students often use multiple languages to make sense of the mathematics (Clarkson, 2009). In these moments, teachers face decisions as to how to support students' multilingual sense-making practices and/or to find ways to encourage students to use the prescribed language of instruction (Farrugia, 2013). This dilemma of code-switching refers to whether teachers and/or their students should switch between languages to support students' mathematical understanding and language development, or maintain a focus on the language of instruction (in this case, English) (Adler, 2002, pg. 73).

Other studies have documented similar tensions. For example, also in South Africa, Setati (2005) found that even when teachers shared the home languages of their students, English functioned "as the language of mathematics, authority, and assessment" (p.447) because of the privileged position that English held in South African politics and economy. While navigating the positioning of multiple languages in the mathematics classroom can be challenging, research has shown that when teachers encourage multilingual students to use their first language(s) in the classroom (reflecting a particular response to Adler's dilemma of code switching), this empowers students and supports academic success (Gutiérrez, 2002; Gutstein, Lipman, Hernandez, \& de los Reyes, 1997; Turner et al., 2013b).

Dilemmas as an analytic device and source of praxis. In summary, Adler argued that the framing of teaching dilemmas serves as an analytic device for researchers, as well as a source of 
praxis for teachers. This use of dilemmas allows researchers to frame what they study and it supports teachers in exploring their own instructional decisions. While research has begun to document the practices and dilemmas of elementary teachers related to language in the linguistically diverse mathematics classroom (e.g., Adler, 2002; Khisty \& Chval, 2002; Setati, 2005, 2012), more empirical work is needed to understand how theoretical perspectives on teaching mathematics in linguistically diverse settings apply to and are evident in teachers' practice.

In particular, few studies have investigated teachers' practices and dilemmas related to language and language learners in their early career mathematics instruction (Janzen, 2008). A focus on this sub-group is important because early career teachers (ECTs) are often challenged by teaching with less support than preservice teachers, while they have not yet developed practices to manage the varied complexities of classroom teaching (Long et al., 2012). Additionally, understanding what is accessible and challenging for ECTs related to language and language diversity in mathematics teaching is important as it can inform teacher preparation and new teacher induction programs. To address this research need of applying theory to practice, this study is guided by the following research question: As ECTs plan, enact, and reflect on mathematics lessons in linguistically diverse mathematics classrooms, what language perspectives and dilemmas related to language are evident in ECTs' understandings and practices?

\section{Methods}

Using a qualitative case study design (Creswell, 2013; Stake, 1995; Yin, 2013), we investigated the practices of six early career elementary and middle school mathematics teachers. Case study research lends itself to "how and why questions" regarding social phenomena, especially questions that require "extensive and in-depth description" (Yin, 2013, p. 4). This study is suited for case study because it seeks to understand a complex phenomenon: how ECTs consider language 
and enact practices focused on language in their mathematics instruction. Correspondingly, we examined patterns across cases to understand ECTs' practices (Stake, 2006; 2013).

\section{Participants}

The ECTs attended one of two universities located in different regions of the U.S. They participated in the larger [project name] study starting in their university mathematics methods course and through the end of their first or second year of teaching (see Turner et al,, 2012). We selected participants to reflect the diversity of preservice teachers from the original methods courses, they agreed to participate in classroom observations and interviews, and they worked in teaching contexts that included language learners (often Spanish/English emerging bilinguals). Participants included teachers in grades K (5-6 year old children) through grade 7 (12-13 year old children) (see Table 1). The language of instruction in participants' classrooms varied (from English-only instruction, to varying models of bilingual [Spanish/English] instruction), which allowed us to investigate teachers' understandings and practices related to language across a range of instructional contexts.

\section{[Insert Table 1 here]}

\section{Data Sources}

Data sources included classroom observations of mathematics lessons, coupled with preand post-observation interviews. We clustered observations for two to three consecutive days in order to observe a sequence of mathematics lessons. We observed 8-12 mathematics lessons per ECT, per year. We recorded scripted field notes for each lesson (recording discourse in script format, along with gestures, actions, visual representations, etc.), and collected artifacts including photos, lesson plans, and student work samples. We conducted pre-observation interviews prior to each cluster of lessons, and post observation debriefs for the first and final lesson of each cluster. These interviews (approximately 30 minutes each) probed ECTs' perspectives, decisions, and 
reasoning, and provided opportunities for ECTs to recount, interpret, and respond to key moments from lessons, including goals and reflections related to language. We also conducted interviews at the beginning, middle, and end of the year to capture reflections about teaching and learning across the year, and information about their teaching contexts (e.g., professional development, curriculum, assessment, policies). All interviews were audio recorded and transcribed for analysis.

\section{Data Analysis and Analytical Framework}

Through multiple and iterative cycles of analysis, we conducted within-case and cross-case analyses for these cases of teaching (Creswell, 2013; Stake, 1995). After developing a preliminary codebook based on language practices identified in the literature and evidenced in our data, we engaged in cycles of coding and writing analytic memos to identify themes (Miles, Huberman, \& Saldaña, 2014). Table 2 shows these codes and the operational definitions we used in applying the codes.. We also developed decision rules for the coding process. For example, we defined a stanza (Saldaña, 2013) of text as both the question and the participant's response, as well as additional text needed for context. We coded all field notes and transcripts using a qualitative analysis software HyperResearch (Researchware, 2011). To achieve interpretive convergence (Saldaña, 2013) and ensure consistency, two researchers independently coded one third of the transcripts, and met to resolve any discrepancies.

[Insert Table 2 here]

After coding the data, we generated a narrative compilation (Creswell, 2013) of practices related to language for each of the six ECT participants. These compilations included representative and compelling examples, along with non-examples, from all data sources to test emerging themes (confirming, refuting, or investigating further). Through these phases of analysis, we identified patterns for ways the three language perspectives (i.e., lexicon, register, and situated-sociocultural) were evidenced across the ECTs' practices. In analyzing for these perspectives, we applied the 
descriptions of each of these perspectives described earlier in the section on "Perspectives Related to Language." We continually consulted the literature as our findings emerged in order to investigate how these theorized perspectives might apply and intersect in the ECTs' practices. After creating narrative compilations, in addition to identifying ECTs' practices relative to language perspectives, we recognized patterns related to teaching dilemmas (Adler, 2002). At that point, we applied Adler's framing of teaching dilemmas in relation to language to our data and previous analysis. Our goal was to identify key dilemmas both within and across cases (e.g., some ECTs explicitly voiced a dilemma within a lesson, yet in other instances, a dilemma was not explicitly stated, but instead was evidenced by ECTs' decisions around language). This approach to analysis is consistent with Adler's (2002) research: she contends teachers did not necessarily explicitly identify situations or decision as a "dilemma." Note that in our analysis and findings, we did not aim to classify each ECT as working from a single perspective or wrestling with a specific dilemma; rather, we focused on identifying instances when a particular perspective and/or dilemma was evident. As Adler (2002) argued, when theory is applied to practice, teachers might apply hybrid version of theories, so we remained open to this possibility with our analysis and findings. Moreover, we recognize that our data represents snapshots in time of ECTs' and students' work and interactions, so classifying ECTs based on our data would not be appropriate.

In a final phase of analysis, we continued to look across the ECTs' cases for similarities and differences in patterns. These patterns, comparisons, and contrasts prompted additional conjectures that we then confirmed or refuted by re-examining data.

\section{Findings}

We present our findings for the six ECTs language-related practices in their mathematics instruction. The first section provides a broad overview of the practices that these ECTs used and 
the language perspectives evidenced in these practices. The second section identifies dilemmas that emerged across these practices.

\section{Patterns in ECTs' Practices related to Language and Language Learners}

Our findings highlight patterns in ECTs' practices related to language and language learners in their mathematics teaching. While we view the three perspectives on language in mathematics $t$ as nested (i.e., lexicon, register, and situated-sociocultural), we organized ECTs' practices according the perspective most evident in instructional moves and decisions, with attention to inconsistencies and possible movement towards other perspectives. Doing so allowed us to analyze and highlight when and how each perspective was evident in ECTs' practices to understand the complexities and interplay among these views on language. We illustrate each pattern in ECTs' practices with brief examples from selected ECTs' lessons.

Lexicon perspective: Multiple opportunities to hear, see and say, key terms. One theme evidenced across our six cases was that ECTs planned for and supported regular opportunities for students to hear, see, and say mathematical vocabulary. This focus on mathematical terminology, which often reflected a lexicon perspective (Dale \& Cuevas, 1987; Rubenstein, 1996), is not surprising, as numerous researchers argue for explicit teaching of academic language for language learners (Ballantyne, Sanderman, \& Levy, 2008; IES, 2014; Lesaux, Kieffer, Kelley, \& Harris, 2014). For example, all six ECTs used visual reminders like vocabulary word walls to prompt students' use of mathematical language. Moreover, ECTs provided multiple opportunities for students to say and define key mathematical terms in lessons (e.g., turn and talk to a neighbor, say it to the ceiling, tell your pencil, choral response). For instance, in Elena's lesson on two-dimensional figures, she provided multiple opportunities for using mathematical vocabulary through choral response strategies (e.g., lados [sides] say it with me -lados!) and by displaying key terms on vocabulary anchor charts that she co-created with students. She also emphasized opportunities for 
students to hear key vocabulary and definitions from their peers, knowing that peer explanations can support understanding (e.g., ". .. because they were able to see it [the new term], and hear it from them [a friend], and they were able to understand") (Post-lesson interview).

During group discussions and in their writing, ECTs reminded students to use key vocabulary, and when students did not use the identified words, ECTs prompted students to revise their statements. In some instances, the ECTs offered scaffolds such as sentence frames to support students' use of vocabulary. This move may have reflected emergent understandings consistent with a register perspective. Namely, it is not sufficient to focus solely on terminology, grammatical structures also create complexity for students. In short, ECTs aimed to support students in focusing on relevant mathematical vocabulary, and to encourage students to use the vocabulary as they completed lesson tasks. These findings echo research that has documented ECTs' tendency to focus on vocabulary, albeit in meaningful ways, over other language demands in teaching and learning mathematics (Schleppergrell, 2007).

\section{Lexicon perspective: Connecting key vocabulary to students' prior knowledge and} experiences. In other instances, instead of emphasizing vocabulary by first presenting terms and then calling for rote repetition, the ECTs focused on vocabulary in ways that supported sense making and connections to underlying concepts. Specifically, five of the six ECTs introduced new mathematical vocabulary by asking students to generate definitions, descriptions, and examples based on their own experience and knowledge. For example, to launch a set of lessons on similar figures, Evelyn asked students to "define similar in your own words" and to record their definitions in their math journals. She purposefully omitted definitions on class anchor charts because she wanted students to generate definitions that made sense to them. In some lessons, ECTs also delayed formal definitions of terms until after students had multiple opportunities to think and talk about the meanings of words. 
Interestingly, ECTs' reasons for connecting new vocabulary to students' prior knowledge varied. For Elena, these connections helped students move beyond memorized definitions, towards understanding. Evelyn believed that linking new vocabulary to students' ideas and experiences made the terms "memorable" for students. For Estelle, connecting to students' prior knowledge and experience was a way to address confusions related to teacher-generated definitions. While reasons varied, all instances in this theme evidenced introducing vocabulary via connections to students' experiences; we did not find any instance in which ECTs introduced vocabulary in a rote, definition-first manner. This suggests that while the ECTs were primarily focused on teaching vocabulary (reflecting a lexicon perspective), they were able to do so in ways that connected to children's experiences, perhaps evidencing an acknowledgement of the role of everyday experiences in supporting mathematics learning and a possible extension of the lexicon approach towards a situated-sociocultural perspective.

\section{Lexicon and register perspectives: Precise and regular use of mathematical language.}

While all ECTs in our study foregrounded vocabulary, five of the ECTs evidenced attention to how students used language as they worked on lesson tasks, in ways that reflected both lexicon and register perspectives on language. These ECTs emphasized precise use of mathematical language, consistent with Mathematical Practice 6 (NGACBP \& CCSSO, 2010) ${ }^{2}$. For example, as Padma monitored small group work, she pushed students to use mathematical terminology both orally and in writing, and to precisely describe and represent their strategies and the quantities involved. Other ECTs communicated clear expectations that students use mathematical vocabulary during class discussions (e.g., Elena, Evelyn). Notably, teachers' moves related to precision were often in response to what they heard or saw students do relative to mathematical language. In other words,

\footnotetext{
${ }^{2}$ Note: for this theme and others in the paper, we are not claiming that the other teachers did not engage in this practice; rather, we only have evidence for some of the teachers demonstrating this practice in our data set.
} 
ECTs focused on students' language use during lessons, and provided in-the-moment responses to encourage precision. For example, when Natalie heard a student give a measurement (the length of his shoe) without the corresponding units, she prompted the student to revise his sentence by asking, "Six what?" When the student identified the unit (6 cubes long), Natalie responded with humor, "Good, I was worried it was 6 elephants long!" and also with a probe to consider why precision is important, "Why is it important to tell Mr. Shoe salesman the units you were measuring? Similarly, when Evelyn noticed that a student explained a concept without using the associated mathematical terminology, she frequently asked, "what's a vocabulary word that you could have used?" This finding suggests that one way ECTs supported precise and meaningful use of mathematical language was by closely attending to students' contributions, and responding with a press for clarification or refinement. Consistent with the nested nature of the perspectives of language, these practices reflected both a lexicon perspective (i.e., the focus on learning and using specific words), as well as a register perspective (i.e., the focus on the mathematics register, and precise communication of mathematical quantities and ideas).

Situated-sociocultural perspective: Connections to multiple languages. We found that most ECTs evidenced a resource-based orientation to students' home language (in these cases, Spanish) that was consistent with a a situated-sociocultural perspective. They viewed connections to students' home language during mathematics lessons as supportive of student learning, and evidenced multiple teaching moves consistent with this position (e.g., Evelyn encouraged students to work in languages other than English during mathematics lessons; Elena revoiced English contributions by students in Spanish as a way of promoting mathematics terminology in Spanish). Similar to previous findings, ECTs' reasons for including multiple languages in mathematics instruction varied. Estelle focused more on student participation in mathematics lessons, and noticed that when she included spontaneous connections to students' home language, increased 
engagement resulted. Elena noted that she noticed an increase in students' understanding when concepts were introduced in Spanish. Yet for each of these ECTs, their practices related to multiple languages reflected a situated-sociocultural perspective on language in mathematics, as they focused on opening and supporting spaces for students to communicate and participate in multiple ways. However, we found more variance in ECTs' perspectives and practices related to multiple languages, particularly as contrasted with the other themes. We elaborate on these contrasts in the subsequent finding section on teaching dilemmas.

Situated-sociocultural perspective: Emergent focus on mathematical discussion. While researchers have established that scaffolded mathematical discussions can have a positive impact on students' linguistic and identity development (Turner et al., 2013a, 2013b; Moschkovich, 1999), we found that the ECTs in this study utilized mathematical discussions to varying degrees, and for varying purposes. Natalie, Padma, Kara, and Evelyn regularly used brief mathematical discussions to support their students' mathematical and linguistic development, yet for Elena and Estelle, this was a more infrequent practice. For example, Kara frequently asked students "How do you know?" as part of her "prove-it moves" designed to elicit students' explanations and justifications. When students hesitated (e.g., "I don't know"), rather than stepping in and taking over the conversation Kara continued to probe, asserting confidence that the students could explain their thinking (e.g., 'I know that you do."). In these instances, Kara typically did not push students to use formal language, and instead, she insisted that they describe and justify their methods in their own words. Kara noted that opportunities for students to explain their reasoning students' supported language development and understanding, "It makes it more concrete" (Post-lesson interview). Apart from these instances in Kara's classroom, discussions were typically brief, and teacher-directed. This finding in combination with varied and infrequent use of discussions from other ECTs suggests that facilitating mathematical discussions was an emerging and challenging practice for ECTs. 
Summary of patterns in ECT practices related to language and language learners. As part of a broad focus on mathematical vocabulary, we found variation in ECTs' practices for introducing and supporting mathematical language, and different ways that ECTs' practices reflected perspectives on languages outlined in the literature (Moschkovich, 2002). One important contribution of our findings are insights about how different perspectives on language might be operationalized, in varying ways, in teachers' practices. Notably, we found variations in practice both across the group of six ECTs, and within the practices of a single ECT, which supports our interpretation of these perspectives as nested (one extending the other). For instance, some ECTs evidenced practices that suggested a situated-sociocultural perspective on language and mathematics (i.e., a focus on negotiating meanings in context), but in other instances reflected lexicon perspectives (i.e., choral response of vocabulary words and definitions), or emphasized the mathematics register (i.e., probing for precision in explanation, and use of units to describe measures). However, while this hybridity of perspectives was evident across the ECTs, each teacher's practice seemed to foreground particular perspectives (e.g., the lexicon perspective). ECTs' divergent motivations for enacting particular practices related to language in mathematics suggest that it is important to attend both to teachers' practices, and also to query teachers' reasoning and reflections on these practices, as this provides insights into the perspectives underlying particular practices. We return to this point later, in our discussion of implications.

\section{ECT Dilemmas Related to Language and Language Learning}

The second section of our findings highlights three dilemmas related to language and language learners in mathematics teaching that we identified in our analysis. We first describe each dilemma, and then use focal lessons from selected ECTs to illustrate how the dilemma was evidenced in practice. The ECTs highlighted for a given dilemma reflect the dilemmas most prominent in an individual ECT's language-related practices. 
Dilemma 1: When and how to introduce vocabulary. As summarized above, all the ECTs in our study foregrounded mathematical vocabulary, and provided ongoing opportunities for students to hear, see and say key terms. That said, their practices varied considerably, and reflected different ways of negotiating complexities related to how and when to introduce new vocabulary to students, such as: Should vocabulary be introduced at the beginning or the end of a lesson? Should definitions be provided by teachers, or generated by students? Should teachers present examples of a new term to students, or should students be responsible for generating their own examples? What is the best way to connect new vocabulary to students? Teachers' practices reflected a range of responses to these dilemmas, as illustrated in the following lesson vignettes.

\section{Challenges related to front-loading new vocabulary: Estelle's $2^{\text {nd }}$ grade lesson on}

multiplication. In this focal lesson, Estelle's goals included learning key vocabulary and understanding how arrays model multiplication. During the lesson students drew arrays to solve multiplication word problems (e.g., There are 3 rows of lettuce. Each row has 6 heads of lettuce. How many heads of lettuce in all?) (see Figure 1), and to represent basic multiplication facts (e.g., 6 $\mathrm{x} 3$ ). As was typical, Estelle began this lesson by reviewing key vocabulary with students, using words, definitions, and pictures on a large anchor chart (see Figure 2). Estelle read the terms aloud (i.e., row, column, array) and students repeated each term in a choral response, with associated movements (i.e., hands move up and down [vertically] for column, and side-to-side [horizontally] for row). Estelle emphasized that without explicit attention to unfamiliar terms at the beginning of the lesson, students may have limited access to the mathematical tasks. In her words, "I feel like if they can't understand the words that we're using, the mathematical terms, they're going to have a really hard time understanding the concepts" (Post-lesson interview). 
However, during the lesson, Estelle noticed that some students were confused by the terms rows and columns ${ }^{3}$. She was faced with a dilemma of whether she should explicitly address students' uncertainty with the vocabulary. Her initial response was to intervene, and to review the terms and the associated movements, a practice which she believed to be particularly beneficial for language learners.

Some of the students were still having a hard time figuring out which ones were the rows, and which ones were the columns. ... Some of them said, "Oh, what's the column way again?" I said, "Do you remember the move?" They went, "Oh, yeah. Up and down." [hands move up and down]. And I taught them a little move for them to remember .... A row goes side to side, so I made them do a little twist side to side. ... Because I have so many English language learners in my class, I think that really helps them. (Post-lesson interview)

Later in the lesson, when some students continued to struggle to identify rows and columns in representations, and to use arrays to solve problems, Estelle faced a similar dilemma. She had to decide whether to intervene, and if so, whether she should review terms and associated movements again, or pursue a different approach. She opted for a new strategy, pausing students' work on the task for a whole class discussion about everyday examples of arrays, columns and rows. She asked:

Estelle: Where do you see arrays in everyday life? I see them right here in the classroom. [Estelle points to a chart on a classroom bulletin board.] How many rows do you see? How many columns? [Students count rows and columns] Where else do you see arrays?

Student A: The job calendar

\footnotetext{
${ }^{3}$ Throughout the Findings, key mathematics vocabulary is italicized. In cases when a teacher or student says a term with added emphasis (e.g., spoken loudly and/or more slowly) the terms are bolded and italicized.
} 
Estelle: Yes, there are 3 columns of 5, for a total of 15.

Student B: The fake fish on the wall! ...

Student C: The student cubbies! (Lesson field notes)

Students generated additional examples of arrays, and for each example, Estelle asked students to identify "How many rows?" and "How many columns?" and "How many in all?" Estelle concluded by asking students to write three facts about arrays, and to share their thinking with the class. These strategies were aimed at helping students connect key terms with familiar, everyday objects, so that they could make sense of and use the vocabulary (and associated concepts) as they worked on tasks.

Reflecting on the lesson, Estelle noted that her initial introduction of vocabulary was not effective for all students. She attributed students' confusion to the "unfriendly" definitions included on her anchor charts, explaining, "The definitions [of the vocabulary words] on those posters, I

don't think they were $2^{\text {nd }}$-grade-friendly. I had to break them down into simpler terms" (Post-lesson interview). While Estelle maintained that introducing vocabulary at the beginning of each lesson was essential to student success, in response to student confusion she began to consider alternate approaches to teaching new terms such as eliciting students' ideas and connecting to everyday examples. In other words, as she negotiated complexities related to when and how to teach mathematical vocabulary, Estelle began to move towards practices that focused on making meaning of mathematical vocabulary, rather than simply hearing, seeing and saying key terms.

Introducing vocabulary in context: Natalie's Kindergarten lesson on linear measurement. In Natalie's focal lesson, which addressed linear measurement and units of measure, students first outlined their shoe on paper, and then used connecting cubes to measure and record the length of their shoe print and other shoe prints provided by the teacher. Natalie began the lesson by making connections to a familiar setting and activity (i.e., purchasing shoes at a shoe store) to contextualize the mathematical concepts and vocabulary (length and measure). She explained: 
I kind of hooked them in with ... talking about something that they could all understand more or relate to....They all had shoes, and they knew that they needed to be the right size. ... and then we talked about [how] you need to tell the shoe salesman that you need, what size shoe you want ... Then we talked about why they would want to need to measure it the right way. (Post-lesson interview)

In other words, given the dilemma of whether to explicitly teach new terms at the beginning of the lesson, or to allow mathematical language to arise as part of lesson activities, Natalie opted for the latter option. She introduced mathematical language in context, foregrounding ways that the language is used in everyday settings to communicate and make meaning. She began this discussion by eliciting her students' experiences at shoe stores.

Natalie: How many of you have been to the store and needed to buy shoes? [All students raise their hands and begin talking.] What if you went shopping with your mom, and she forgot to measure your feet and she picked out a shoe that was this big? [Natalie pulls off her own shoe and has a student put her foot into it. The students laugh.]

Natalie: What if the shoe your mom brought home was too small? [The students respond that they could not wear it, and that they would have to exchange it for the right size.]

Natalie: Who thinks they know a good way to measure their shoes?

Student A: Take your shoe off.

Student B: You could start off with three cubes together, and hold them up to your shoe. [Natalie asked the student who offered that last suggestion to come up and show everyone what he was thinking.] (Lesson field notes).

As the conversation continued, Natalie created opportunities for students' to repeatedly hear and say new mathematical terms. She highlighted key vocabulary through voice inflection (e.g., as shown above with measure), and provided multiple vocabulary supports (e.g., prompting students to 
say terms to a partner, providing sentence frames with terms included). Yet in each case, she related the mathematical language to a familiar context - measuring feet and purchasing shoes that are the "right size" -inviting students to consider the importance of measuring and to explore ways to use language related to measurement to communicate ideas. For example:

Natalie: When we go to the shoe store.... There are some very specific words that we are going to use, such as length. Say length. [Students say length in a choral response.]

Natalie: Say it to the ceiling! [Students say length in a choral response, as they shout and look up at the ceiling.] Okay, you can also use the word long. So when you go to the shoe store, and the person working there asks you, "What is the length of your shoe?" You would say to the person working there, "I need a shoe that is 8 cubes long ". ... "The length of my shoe is 8 cubes long." Turn to a neighbor real quick and say, "The length of my shoe is cubes long." [Students turn to their neighbor and use the sentence frame].

Natalie: [Student D] come up and tell us what you would say. Say it with me, "Mr. Shoe salesman, the length of my shoe is 5 Cubes long." [Student repeats.] (Lesson field notes) During this discussion, students heard or said length 11 times, with emphasis given to the term in most instances. It is clear that Natalie attended to the need for students to repeatedly say and practice new terms. However, as Natalie was faced with decisions related to how and when to introduce new mathematical vocabulary to students, she consistently opted to introduce mathematical language in the context of familiar scenarios or everyday practice, foregrounding how mathematical language is used to make meaning.

Experiences first, then an emphasis on vocabulary: Kara's $5^{\text {th }}$ grade lesson on fractions and least common multiples. Kara's focal lesson introduced different strategies for adding and subtracting fractions with unlike denominators. During the lesson, students used physical models (e.g., fraction tiles) to represent equivalent fractions and to simplify fractions, and learned strategies 
for rewriting pairs of fractions so that they had a common denominator (e.g., finding the least common multiple). In contrast to both Estelle and Natalie, Kara responded to dilemmas related to how and when to introduce mathematical vocabulary with an explicit decision to introduce key terms after students engaged with a task and developed a need for the terminology.

For instance, during this lesson, Kara asked students to skip count by three and by four on a hundreds chart, and to shade the multiples of each number using different colors. Next, students listed the multiples common to both numbers. Then, Kara introduced the terms common multiples and least common multiple to describe specific numbers in students' lists.

Kara: Okay, we skip counted by threes and fours. What is special about these things? ... Turn and talk to your neighbors to share ideas. ... [Students briefly turn and talk] Student: They are all multiples.

Kara: Okay so they are common multiples. [She writes Common Multiples on the anchor chart.] What does common mean again?

Student: The same.

Kara: So if common means the same, and I had you write down common multiples, what are they common multiples of?

Students: 3 and $4 \ldots$

Kara: All of these numbers are common multiples of 3 and 4 . Now...12 is special, why? Student: It is the first one.

Kara: Okay, I like your thinking. What is it?

Student: It is the smallest multiple.

Kara: [Writes the word Least down on the anchor chart.] What does this word mean? Turn to a partner and tell them what least means. [Students turn and talk]

Student: It means smallest. [Kara has student write down "smallest" on the anchor chart] 
Kara: Okay so 12 is the smallest number that they have in common, it is the least. It is the least common multiple. (Lesson field notes)

After introducing new vocabulary, Kara expected students to use the words. For example, as the lesson continued, she encouraged a student to use least common multiple in his explanation:

Student: I counted.

Kara: What do you mean you counted?

Student: I started with 8 and skip counted by 8 . Then I also skip counted by 12 , until I found the number that both had in common.

Kara: So this is what I want you to say, "I skip counted by 8, and I skip counted by 12 until I found the least common multiple which was 24." [Student repeats] (Lesson field notes) Reflecting on the lesson, Kara explained that when faced with decisions about whether to frontload vocabulary, or to address mathematical language later in the lesson, she purposefully decided to introduced vocabulary after students had experiences with the concept, "to get [students] thinking more instead of telling them." (Post-lesson interview). In other words, and in contrast to the other ECTs in our study, Kara first invited students to experience mathematical ideas (e.g., by solving tasks), and then used these experiences to motivate the introduction of key terms.

Responses to the dilemma of when and how to introduce vocabulary. In summary, the ECTs in our study evidenced different ways of negotiating the dilemma of how and when to introduce new mathematical vocabulary to students. While they generally foregrounded vocabulary, introducing and defining new terms at the beginning of each lesson (reflecting a lexicon perspective), their practices also reflected careful attention to student understanding, and to the specific learning needs of language learners (i.e., visuals, gestures, anchor charts, and repeated opportunities to hear and say new words were common). They realized that teacher-generated definitions were often insufficient (Estelle), and that students needed opportunities to engage with 
new language in context, including everyday contexts and scenarios (Natalie, Estelle) and mathematical contexts (Kara). In other words, while the ECTs' practices generally aligned with a lexicon perspective that foregrounds vocabulary acquisition, in other instances ECTs evidenced attention to how mathematical language is used to communicate ideas and negotiate meanings (Natalie), consistent with a situated-sociocultural perspective. Shifts towards introducing new vocabulary in context or connected to everyday settings often seemed to be in response to unsuccessful attempts to explicitly teach vocabulary in ways that were disconnected from students' experiences (Estelle). These findings showing a range of teacher actions evidence that the dilemma of when and how to introduce mathematical vocabulary to students is complex. In response to this dilemma, we found ECTs enacting practices based on different language perspectives, and in some instances, demonstrating practices that reflected a hybrid of perspectives.

\section{Dilemma 2: When, how and why to intervene with students' use of mathematical}

vocabulary. As noted above, five of the ECTs in our study emphasized precise use of mathematical language as students worked on lesson tasks. Yet their practices varied considerably, and reflected different ways of negotiating complexities related to when, how and why to expect students to use mathematical language and terminology. ECTs' practices reflected different responses to dilemmas such as: Should students be expected to use mathematical language in group discussion, and/or in writing, and/or in choral response? And for what purposes? Should teachers intervene when students do not use "target" vocabulary, or allow students to continue their work on the task? The following lesson vignettes illustrate teachers' varied responses to these dilemmas.

\section{Using key vocabulary indicates understanding: Padma's $4^{\text {th }}$ grade lesson on perimeter}

and area. In Padma's focal lesson, students found the area of squares and rectangles using tiles and grid paper, and determined dimensions for rectangles with given perimeters. Padma's goals were for students to differentiate accurately between area and perimeter, as well as use key mathematical 
vocabulary (i.e., measurement, area, perimeter and square units). At the beginning of the lesson, Padma drew students' attention to an anchor chart with "million dollar words" that Padma expected the students to use in their group discussions and writing. Padma argued that it was important for students to use the target vocabulary, because, "if they [students] can use the vocabulary...it shows that they have better understanding of what the concept is" (Pre-lesson interview). For example, in this excerpt, Padma introduces area as a new "million-dollar word".

Padma: The last few days you have been finding the outside of shapes or perimeter. Today you are going to find the inside of the shape.

Student A: That's the area.

Padma: Yes, that is our million-dollar word. Area. Turn and talk to your partner about what area means. [Students work in pairs; Padma calls on a student to share definition.]

Student B: It is the inside of a shape. (Lesson field notes)

Later in the discussion, Padma reviewed the key term perimeter by reminding students of a task about an ant walking around a paper.

Padma: What did the ant do?

Student C: The ant walked around the outside or edge of the paper.

Padma: What do we call the outside of a shape when we measure it?

Student D: Perimeter.

Padma: Turn to a partner and share your definition of perimeter. (Lesson field notes)

As the lesson continued, and Padma was faced with decisions about whether to intervene if students did not use precise mathematical language, Padma frequently opted to prompt students to use these "million dollar words" (i.e., area and perimeter). She explained, "so if they were doing a word problem, and explaining how they solved it, the students' job was to try and incorporate it [the million-dollar word]" (Teacher Study Group). For example, as one student was explaining his 
solution in writing, Padma challenged him, "to use as many million-dollar words as possible" (Lesson field notes).

Padma's focus on million-dollar words reflected her broader emphasis on precise use of mathematical language. For example, as students calculated the perimeter of specific figures, one student labeled each side " 25 " without noting the units. Padma asked the student, "What is the 25 ? Is it feet? Inches? Puppy dogs?” and the student was unsure. Next, Padma suggested that he reread the problem for clues. Once the student determined that the problem described a garden measured in feet, Padma returned to the label of " 25 " and asked the student to restate the length of the side this time with more precision (i.e., "25 feet"). Throughout the lesson, Padma emphasized students' use of the terms area and perimeter as well as appropriate terms for units, in alignment with her professed belief that the regular and precise use of mathematical vocabulary supported language learning (i.e., 'I wouldn’t remember any vocabulary words unless I use them” [Teacher Study Group]). Moreover, Padma explained that when students used mathematical vocabulary as they worked on lesson tasks (i.e., "the kids were using the actual vocabulary accurately"), this indicated student understanding (Post-lesson interview).

Using common mathematical language to promote communication and understanding in the classroom: Evelyn's $7^{\text {th }}$ grade lesson on coordinate graphing. In Evelyn's focal lesson, students graphed points on a coordinate plane, connected the points to form a polygon, and then enlarged or shrunk the polygon proportionately by scaling the coordinates (e.g., doubling or halving coordinates). Students also used coordinates, side length, and angles to analyze sets of figures and determine similarity. Similar to Padma, Evelyn attended closely to students' use of mathematical language during group discussions, and prompted students to refine and elaborate their ideas when the meanings were unclear. Yet when faced with decisions about how to intervene when students did not use precise mathematical vocabulary, Evelyn typically focused less on students' use of 
specific terms, and more on how students articulated their ideas and thinking. For example, during the similar figures lesson, she pushed students to explain the impact of multiplying the coordinates by different values, probing students to refine explanations that were unclear.

Evelyn: What will happen if we multiply [each point] by 1.5 ?

Student: It gets bigger. The points get bigger.

Evelyn: The points get bigger? Will we have bigger dots?

Student: Oh no, the space will get bigger. (Lesson field notes)

Evelyn found that over time, these guiding probes "got them explaining more" and "thinking about the language and not just the models and strategies that they're using" (Pre-lesson interview). She further explained that "When you just continue giving [students] those opportunities to talk, and to share and to question, they become a lot more comfortable in the subject area" (End of year interview).

At times, Evelyn emphasized students' use of specific mathematical vocabulary, but in different ways, and not as frequently as many of the other ECTs. For example, during the lesson on similar figures, rather than prompting students to use the word similar in their explanations and discussions, Evelyn asked students to talk explicitly about the multiple meanings of the word similar in math and in their everyday experiences. She explained:

Similar in math means something different than similar in real life. I said, "Pick out two students that are similar in the class" ... Then we moved into shapes, "These are similar in this way, but the thing that makes them that vocabulary-word similar is the corresponding lines, and corresponding angles" .... the word [similar] can have multiple meanings, for the benefit of English Learners and students that were not. (Beginning of year interview) Inviting students to discuss the multiple meanings of words was a common practice for Evelyn. 
Later, as she reflected on the similar figures lesson, Evelyn again called attention to students' use of mathematical language as they worked on lesson task. Specifically, she celebrated a small group conversation where students used key terminology as their described their strategies.

I had a few students, they were like, "I don't know what to do since I have all these curves," and students next to them were like, "Frame it. You have to use straight lines." I was really happy with that...[The students] were using that language. (Post-lesson interview) While Evelyn commended students' use of mathematical language, she was also explicit that she emphasized specific terms not because she believed that the use of mathematical vocabulary indicated understanding (i.e., Padma's stance), but because using a shared, agreed upon language supported communication and sense making. She explained that promoting a "common language" in group discussion enhanced communication, noting, "A lot of them [students] have the same ideas, [but] they describe it differently and they're not using that language, so they don't really see the connections" (Pre-lesson interview). In short, while Evelyn encouraged students to use and to reflect on mathematical language, she did so for a different purpose - to facilitate communication and to deepen students' understanding of the multiple meanings of words across contexts.

\section{Responses to the dilemma of when, how and why to intervene with students' use of}

mathematical vocabulary. In summary, the ECTs in our study evidenced different ways of negotiating this dilemma related to when, how and in particular, why to intervene with students' use of mathematical language and terminology. Padma focused on pressing students to use mathematical terminology precisely in order to support their vocabulary growth (in alignment with a lexicon perspective). She also believed that precise use of vocabulary was an indication of students' mathematical understandings. On the other hand, Evelyn encouraged students to use mathematical terminology in order to create a shared linguistic understanding, as part of facilitating classroom interactions (in alignment with a situated-sociocultural perspective). These findings 
showing varied teacher responses to the dilemma of when, how and why to intervene as students learn to use mathematical language reflected different language perspectives. In addition, similar to the first dilemma, even in instances when ECTs' responses to the dilemma were similar (e.g., deciding to intervene in instances when students did not use precise mathematical language), their reasons for specific practices varied (e.g., Padma and Evelyn).

Dilemma 3: The role of multiple languages in the mathematics classroom. While the ECTs generally viewed students' experiences with multiple languages as a resource that supported their learning, we found considerable variance in ECTs' practices related to multiple languages in the mathematics classroom, both within a teacher and across the teachers. More specifically, ECTs' practices reflected different responses to question such as: Should multiple languages be used in mathematics instruction, or should the teacher maintain one language for instruction? And if multiple languages are used, by whom (i.e., the teacher, and/or the students), and for what purposes? What if the teacher only speaks one language, then what does it mean to support multiple languages during instruction? When the teachers' stance towards multiple languages differs from the position or policy at the school, is it reasonable to subvert these policies? The following lesson vignettes illustrate teachers' varied responses to these dilemmas.

\section{Conflicting perspectives and restrictive language policies inhibit multiple languages in}

mathematics instruction: Padma. Padma evidenced different perspectives on the use of multiple languages at different points in mathematics teaching and learning. On one hand, she supported students' Spanish/English bilingualism (e.g., 'I try to make it very clear [to students] that knowing Spanish is a great thing, but I also want students to learn English as well as know Spanish." [Postlesson interview]). On the other hand, she positioned English as the only language of school mathematics when she said, 'The kids asked me, 'Is it okay to speak Spanish in the classroom?' I said, 'Well, my job is to teach you English. Let's speak English.'” (Post-lesson interview). Padma 
explained that the school's philosophy regarding speaking any language other than English was that, 'It can't happen ... [because] we're here to teach the students English" (Post-lesson interview). Padma's unfamiliarity with Spanish, the home language of most of her students, also inhibited her ability to connect to multiple languages in her teaching. In her words, "It's harder for me [to make connections to Spanish] just because I don't really know their language" (End of year interview).

Given her own conflicting perspectives, and the restrictive language policies of her school, when Padma considered whether to allow multiple languages in her classroom, Padma opted not to connect to students' home languages, and instead support students' learning through the use of visuals. For example, as she reflected on the focal lesson highlighted above, Padma explained how she used visual representations to support students who were learning the language of instruction.

[For] a lot of these kids, English isn't their first language. ... To make sure they understand the material, I think about how I can present it in a way that's accessible to everyone regardless of what level of English they're at. For me, that's a lot of visuals. ... The colorcoding was [in the lesson] to visually see the difference between area and perimeter. Area is this white space inside. Perimeter is this line outside. [Students] could visually see I'm drawing my perimeter. I'm writing in the area. (Middle of year, Post-lesson interview) Padma explained that her use of visuals made the mathematical content and language more "accessible" to her students while still adhering to her school's English-only language policy.

\section{Conflicting perspectives and an emphasis on supporting communication in English}

inhibit multiple languages: Estelle. Similar to Padma, Estelle evidenced different stances towards the role of languages other than English in students' mathematics learning at different points in time. On one hand, she noticed enhanced engagement when she asked students how to say particular words in Spanish. For example, during a lesson on telling time, Estelle noted that when she asked students to tell her the Spanish word for clock, "It made them pay a little more attention 
because they could understand more" (Post-lesson interview). On the other hand, Estelle interpreted students' use of English (versus Spanish) as a positive indication of student progress. Estelle noted, 'For the most part...I don't hear any of them speaking Spanish. They're all speaking English. That's good" (Middle of year interview). In another instance, Estelle expressed concern when she noticed students that seemed to struggle to express their thinking in English.

A few students .... have a hard time speaking English and sometimes I worry about them because when they do speak they can't pronounce the words correctly or they just get a little flustered because the words aren't just coming out. I spent lot of time repeating these words and breaking them down so they know what they sound like. (Pre-lesson interview)

When Estelle faced decisions about whether to incorporate multiple languages in her instruction, she positioned English as the preferred language for teaching and learning mathematics, consistent with her district's language policy. Estelle summarized her perspective, noting, "I want them to embrace [their Spanish]. We just use English in the classroom." (Post-lesson interview). In addition, Estelle focused heavily on students' progress with English, particularly their ability to clearly pronounce and articulate words, which she interpreted as an indicator of understanding.

\section{Understandings of the challenges faced by language learners, and a desire to support}

their identities push back on school language policy: Evelyn. Evelyn attended closely to the challenges with mathematical language that some language learners faced. She explained, "I want them feeling confident so that they're not doubting the choices that they make because they feel like they don't know what the words mean" (Middle of year interview). When Evelyn noticed students talking about tasks in Spanish, despite the "English-only" instructional model used at her school, she positioned Spanish as a resource to support learning. During one lesson when a student apologized for working on a task in Spanish (i.e., 'I'm sorry [Ms. K], I can't do that,'), Evelyn encouraged the student to continue (i.e., "I said, "No, keep going!"). Evelyn was aware of lack of 
support her mother experienced as a bilingual student in an English-only setting, and was determined to offer a different experience. For instance, Evelyn explained, "Anytime I have a student that I know is struggling with the language, I think of her [my mother]" (End of year interview). Evelyn noted that encouraging this student to work on tasks in Spanish caused shifts in his participation, when she described, 'He worked it through, and gave me the answer. "Yes! That's fantastic. You did the whole thing right. ... I can't directly teach you in Spanish, but if you solve it that way first and then explain it to me once you've worked it through, that's fine" (Middle of year interview). Evelyn consistently evidenced a resource-based orientation towards the use of multiple languages in mathematics teaching and learning, which was informed by her own (or her family's) experiences.

\section{Language programs and perspectives that embrace multiple languages, and emphasize}

sense making: Elena. In contrast to the other ECTs, and consistent with the 90/10 bilingual education mode in place at her school (which indicated that 90 percent of instruction should be in Spanish, and 10 percent in English), Elena's mathematics instruction was almost exclusively in Spanish. Elena maintained that since most of her students spoke Spanish as their first language, teaching mathematics in Spanish allowed students to deepen their understanding of concepts. Elena also acknowledged that teaching in Spanish could be challenging, such as her occasional uncertainty about mathematical terminology. When Elena (or her students) were unsure about a Spanish term, Elena used a range of strategies such as connections to known vocabulary words to illustrate the concept. Elena described this challenge and her response to it as follows:

Interviewer: How do you explain $3-D$ to the students? ...

Elena: In Spanish, sometimes it's hard [for me]... I tell them, "2-D is flat. It just doesn't have any other sides. It's just on paper, and 3-D pops out at you. It comes out. You can take 
it off of the paper, it has different sides," ... I showed them just a square, [and] then I showed them a cube. I try to emphasize that it pops out at them. (Post-lesson interview) Despite these challenges, Elena explained that her primary goal was to ensure student understanding, and thus she used (and allowed students to use) both Spanish and English as needed. For example, when students answered questions in English, Elena acknowledged the term in English, and also revoiced it in Spanish. When worksheets were only available in English, Elena translated the directions and problems into Spanish, so that students had access to both languages to support their sense making (Post-lesson interview). To help students make connection across languages, Elena displayed anchor charts with cognates (mathematics terms that are similar in Spanish and English, e.g., circle/círculo, triangle/triángulo). In this way, Elena negotiated complexities (and occasional challenges) related to the use of multiple languages in mathematics teaching by focusing primarily on students' sense making - rather than whether she or her students were using (or not using) a particular language in a particular instance. Elena positioned both language (i.e., English and Spanish) as resources to support her students' learning, and provided opportunities for students to leverage a range of linguistic resources to help them make sense and communicate ideas.

Solutions to the dilemma of the role of multiple languages in the mathematics classroom.

In this final dilemma, ECTs' practices and beliefs about the use of multiple languages in the classroom varied. Padma and Estelle both positioned English as the language of mathematics instruction and pointed to students' use of English mathematical terminology as evidence of their learning (with minimal attention to the ways that students' home languages might support understanding). In contrast, Evelyn, who also worked in a school where English was the language of instruction, encouraged her students to use multiple languages when they were working in order to support their ability to communicate regardless of language (evidencing a situated-sociocultural 
perspective). Elena was able to take this stance a step further because she was bilingual herself so she could use whichever language was most beneficial to support students' mathematical and linguistic growth (again, evidencing a situated-sociocultural perspective). Taken together, these ECTs' perspectives and practices showcase how teachers might navigate dilemmas related to the use of multiple languages in the mathematics classroom.

\section{Conclusion and Implications}

Mathematics education scholars (e.g., Moschovich, 2002, 2012; Chval \& Chavez, 2012) and educational policy makers (e.g., CCSSM; Parveva et al., 2011) have increasingly focused on the importance of language in learning mathematics. Yet, much still needs to be learned about the planned and in-the-moment practices that teachers use to develop language in their mathematics classrooms, as well as the dilemmas they negotiate when implementing these practices. This study addressed this need by analyzing ECTs' language related teaching strategies in order to identify: when and how these teachers drew upon the lexicon (Dale \& Cuevas, 1987; Rubenstein, 1996), register (Schleppergrell, 2007), and situated-sociocultural perspectives (Moschovich, 2002); the dilemmas that these ECTs negotiated in relation to language in mathematics teaching and learning; and the responses they developed.

While we understand the three perspectives on language in mathematics to be nested, there was evidence that these six ECTs enacted particular aspects of each of the perspectives at different points during their lessons and in different ways. Consistent with extant research and theory on language perspectives (e.g., Creese, 2005; Tan, 2011), all six ECTs in this study evidenced a strong lexicon perspective (Dale \& Cuevas, 1987; Rubenstein, 1996) by regularly inviting students to hear, see, and say vocabulary. In other words, we found that lexicon-focused practices were accessible. That said, for each of the ECTs, the practice of introducing new mathematical vocabulary moved beyond rote memorization of teacher- or curriculum-defined vocabulary. Indeed, we found that 
ECTs grounded their practices in student meaning making, and in most instances, connections to students' experiences. Moreover, five ECTs leveraged vocabulary as a means of reinforcing the precision required in the mathematical register, both as it applied in the mathematics classroom and in everyday contexts, which suggested that they were also influenced by a register perspective within this primary focus on lexicon.

The nuanced understandings reflected in ECTs' practices for introducing and supporting the use of mathematical vocabulary contribute important insights to current conversations and research regarding the import of teaching mathematical vocabulary (e.g. IES, 2014). For example, the lesson vignettes provide powerful examples of ways that ECTs emphasized how mathematical language is used across different settings to communicate and negotiate meanings (e.g., Natalie's lesson on the use of length and measure and length units in the context of purchasing shoes), and how ECTs connected mathematical vocabulary to students' experiences (e.g., Kara's lesson that provided experiences first, and then vocabulary to name those experiences). That is, these examples deepen current understandings of how language is conceptualized in the mathematics classroom (i.e., the lexicon, register, and situated sociocultural perspectives) by illustrating how ECTs reflect aspects of these perspectives in their classroom practice.

In contrast to this comprehensive focus on vocabulary, the ECTs in this study implemented practices that evidenced the register and situated-sociocultural perspective to varying degrees. For example, only one ECT (Evelyn) explicitly addressed the multiple meanings of words across contexts (register perspective), while four of the ECTs evidenced practices related to mathematical discussion to build student understanding that reflected key tenets of the situated-sociocultural perspective (e.g., multiple resources to communicate ideas and negotiate meanings). Moving forward, we suggest that it is not enough for scholars to call for precision with language and explanations. Rather, we need to better understand how to support teacher learning and practices 
related to all three perspectives, and particularly the mathematical register and situated-sociocultural perspectives, as practices aligned with these perspectives were less evident in our analyses. We also found that when ECTs enacted practices aligned with register and situated-sociocultural perspectives, they often expressed particular reasons for these practices. This indicates that support for teacher learning needs to focus not just on what practices to enact, but also why these practices are important for students' learning.

Future research and professional development could be informed by the dilemmas that we found across these ECTs' practices. The first two dilemmas focused on different ways that ECTs negotiated complexities related to introducing and supporting the use of mathematical vocabulary. In the first dilemma, ECTs evidenced differing practices related to when and how to introduce vocabulary with one ECT favoring a lexicon perspective of front-loading teacher definitions (e.g., Estelle) and others showing a situated-sociocultural perspective by encouraging students to make sense of vocabulary through their own knowledge and experiences (e.g., Natalie and Kara). In the second dilemma, ECTs negotiated divergent beliefs about where, how, and ultimately why students should use mathematical vocabulary, and correspondingly, when to intervene with more explicit prompts for vocabulary. All of the ECTs in this dilemma prompted students to use mathematical vocabulary precisely in various instances, but their reasons for this practice varied. Adler's (2002) work highlighted the dilemma of language versus content, or when to make language visible to support student learning and when to let it be invisible so that students can focus on the mathematics. We found that when ECTs focused on making language visible, and particularly vocabulary, their reasons for doing so varied (e.g., to confirm student understanding - Padma, or to establish shared language and facilitate commination - Evelyn). This extension of Adler's work is significant because our findings reveal more about forms this dilemma takes in teachers' practices. Making language visible is an important skill for teachers in light of findings about the complex and 
intertwined relationship between students' mathematical and linguistic development (Purpura \& Ganley, 2014). Notably, none of the ECTs talked explicitly about making language invisible so that students could focus on the mathematics. This finding suggests that teachers may need additional support as they learn to negotiate when and how to make language invisible.

Our final dilemma focused on how these ECTs viewed the role of multiple languages, and particularly how and whether students' home languages featured in their mathematics classrooms. Adler (2002) found that multilingual teachers negotiated when to code switch with their students during mathematics lessons. In contrast, Setati (2005) found that multilingual teachers may privilege one language for mathematical discussion based on the larger sociopolitical positioning of that language in the school or community. We found similar dilemmas related to multiple language among the ECTs in our study. Specifically, ECTs negotiated whether or not students could and should use multiple languages in the classroom based on language policies that shaped the language of instruction in their schools (similar to Setati, 2005), and also their own stance towards the role of English and other languages. For example, despite contrasting language programs at their school (e.g., bilingual versus English-only), both Elena and Evelyn encouraged English and Spanish in their mathematics classrooms, a move motivated by a belief that connections to students' home languages supported student learning. In a sense, they made the language invisble to use Adler's (2002) term, in that they focused on more students' ideas and understanding, and less on the specific language that was used. In contrast, Estelle discussed instances where she elicited Spanish words from her students as part of her mathematics instruction but positioned this as a move to promote student engagement, not understanding. Finally, Padma evidenced different stances on multiple languages at different points, indicating her ongoing negotiations related this dilemma. On the one hand, she voiced support for students' bilingualis m, and on the other hand, she explicitly stated that during mathematics lessons, she expected students to use English only. These disparate 
positions on the use of multiple languages in the mathematics classroom provide evidence that this dilemma (i.e., when, how, and even if students, and potentially multilingual teachers, should use both the language of instruction and students' home languages) is complex and challenging for teachers to solve. Further, these complexities involve more than the language policies guiding instruction at the school.

Moreover, we found that ECTs' own backgrounds and experiences mattered in how they viewed and acted on language (e.g., Evelyn's stance towards multiple languages in the mathematics classroom was grounded in her understandings of her mother's experiences as an English learner). This finding is important because it suggests that teachers may benefit from interrogating (and perhaps confronting) their own experiences with language and learning, and the ways in which classroom contexts privileged or marginalized the linguistic resources that they brought from experiences outside of school. If teachers reflect on their own experiences and views related to the use of multiple languages in the mathematics classroom, as part of understanding how their views are influencing their instructional decisions, they might be better prepared to plan and enact research-based approaches, rather than relying on their own experiences to drive decisions. This is important because personally-held views based on experiences are often inconsistent with research (e.g., Chval \& Pinnow, 2010), and therefore, we need to explicitly recognize these views and work to shift them.

Ultimately, the language-related practices and the perspectives underlying these practices that teachers enact in their classrooms will impact the mathematical and language learning of all of their students. Understanding the complexities of these practices and perspectives provides an opportunity to support teacher educators and teachers in supporting students' learning. As discussed in the proceeding paragraphs, implications of our findings for teacher education include: increased attention to register and situated-sociocultural perspectives on language in mathematics teaching, 
explicit attention to both specific practices for addressing language in mathematics teaching and reasons or rationales for those practices so that teachers can develop and enact practices with a deliberate stance, and critical interrogation of teachers' own experiences related to language and learning, including ways to challenge or resist restrictive language policies that limit students' access to multilingual instruction. Teacher education should also make explicit dilemma related to language in mathematics, particularly dilemmas related to invisibility (Adler, 2002), to deepen teachers' understanding of how backgrounding specific language and vocabulary, to focus instead on students' mathematical ideas, can at times be productive. While we have discussed implications for what teacher education should focus on in supporting teachers' practices, work remains on how to create these experience in teacher education courses and professional development experiences. For example, case studies might provide ways for teachers to explore approaches to negotiating dilemmas related to language before confronting them in practice. Future studies could investigate this and other approaches to supporting teachers in developing effective practices for teaching language and language learners in mathematics.

\section{References}

Abedi, J., \& Herman, J. (2010). Assessing English language learners' opportunity to learn mathematics: Issues and limitations. The Teachers College Record, 112, 723-746.

Abedi, J. \& Lord, C. (2001). The language factor in mathematics tests. Applied Measurement in Education, 14(3), 219-234.

Adetula, L. O. (1989). Solutions of simple word problems by Nigerian children: Language and school factors. Journal for Research in Mathematics Education, 20(5), 489-497.

Adler, J. (1997). A participatory-inquiry approach and the mediation of mathematical knowledge in a multilingual classroom. Educational Studies in Mathematics, 33(3), 235-258. 
Adler, J. (1998). A language of teaching dilemmas: Unlocking the complex multilingual secondary mathematics classroom. For the Learning of Mathematics, 18(1), 24-33.

Adler, J. (1999). The dilemma of transparency: Seeing and seeing through talk in the mathematics classroom. Journal for Research in Mathematics Education, 30(1), 47-64.

Adler, J. B. (2002). Teaching mathematics in multilingual classrooms. New York, NY: Kluwer Academic Publishers.

Baker, S., Lesaux, N., Jayanthi, M., Dimino, J., Proctor, C. P., Morris, J., Gersten, R., Haymond, K., Kieffer, M. J., Linan-Thompson, S., \& Newman-Gonchar, R. (2014). Teaching academic content and literacy to English learners in elementary and middle school (NCEE 20144012). Washington, DC: National Center for Education Evaluation and Regional Assistance (NCEE), Institute of Education Sciences, U.S. Department of Education. Retrieved from the NCEE website: http://ies.ed.gov/ncee/wwc/publications_reviews.aspx.

Ballantyne, K. G., Sanderman, A. R., \& Levy, J. (2008). Educating English language learners: Building teacher capacity. Roundtable Report. National Clearinghouse for English Language Acquisition \& Language Instruction Educational Programs. Retrieved from http:/files.eric.ed.gov/fulltext/ED521360.pdf

Barwell, R. (2003). Patterns of attention in the interaction of a primary school mathematics student with English as an additional language. Educational Studies in Mathematics, 53(1), 35-59.

Barwell, R. (2005). Integrating language and content: Issues from the mathematics classroom. Linguistics and Education, 16(2), 205-218. 
Barwell, R. (2012). Heteroglossia in multilingual mathematics classrooms. In H. Forgasz \& F. Rivera (Eds.), Towards equity in mathematics education (pp. 315-332). Berlin: Spring Publications.

Bernardo, A. (1999). Overcoming obstacles to understanding and solving word problems in mathematics. Educational Psychology, 19(2), 149-163.

Chval, K. B., \& Chávez, Ó. (2012). Designing math lessons for English language learners. Mathematics Teaching in the Middle School, 17(5), 261-265.

Chval, K. B., \& Pinnow, R. (2010). Preservice teachers' assumptions about Latino/a English language learners. Teaching for Excellence and Equity in Mathematics, 2(1), 6-12.

Chval, K. B., Pinnow, R. J., \& Thomas, A. (2015). Learning how to focus on language while teaching mathematics to English language learners: A case study of Courtney. Mathematics Education Research Journal, 27(1), 103-127.

Clarkson, P. (2007). Australian Vietnamese students learning mathematics: High ability bilinguals and their use of their languages. Educational Studies in Mathematics, 64(2), 191-215.

Clarkson, P. (2009). Mathematics teaching in Australian multilingual classrooms: Developing an approach to the use of classroom languages. In R. Barwell (Ed.), Multilingualism in mathematics classrooms: Global perspectives (pp. 145-160). United Kingdom: Multilingual Matters.

Core Knowledge Foundation. (1998). Core Knowledge Sequence: Content guidelines for grades K8. Charlottesville, VA: Core Knowledge Foundation. 
Creese, A. (2005). Is this content-based language teaching? Linguistics and Education, 16(2), 188204.

Creswell, J. W. (2013). Research design: Qualitative, quantitative, and mixed methods approaches. Los Angeles, CA: Sage Publications.

Dale, T., \& Cuevas, G. (1987). Integrating language and mathematics learning. In J. Crandall (Ed.), ESL through content area instruction: Mathematics, science and social studies (pp.9-54). Englewood Cliffs, NJ: Prentice Hall.

Dominguez, H. (2011). Using what matters to students in bilingual mathematics problems. Educational Studies in Mathematics, 76(3), 305-328.

Farrugia, M. T. (2013). Moving from informal to formal mathematical language in Maltese classrooms. International Journal of Bilingual Education and Bilingualism, 16(5), 570-588.

Farrugia, M. T. (2015). Creating a Maltese Register for Mathematics in Malta. Malta Review of Educational Research, 9(1), 79-97.

Forman, E. A., Larreamendy-Joerns, J., Stein, M. K., \& Brown, C. A. (1998). 'You're going to want to find out which and prove it": Collective argumentation in a mathematics classroom. Learning and instruction, 8(6), 527-548.

Gee, J. (1999). An introduction to Discourse analysis: Theory and method. New York: Routledge.

Gorgorió, N., Planas, N., \& Vilella, X. (2002). Immigrant children learning mathematics in mainstream schools. In G. de Abreu \& N. Presmeg (Eds.), Transitions between contexts of mathematical practices (pp. 23-52). Springer: Netherlands. 
Gutiérrez, R. (2002). Beyond essentialism: The complexity of language in teaching mathematics to Latina/o students. American Educational Research Journal, 39(4), 1047-1088.

Gutstein, E., Lipman, P., Hernandez, P., \& de los. Reyes, R. (1997). Culturally relevant mathematics teaching in a Mexican-American context. Journal for Research in Mathematics Education, 28(6), 709-737.

Hernandez, N. G. (1999). The mathematics-bilingual-education connection:Two lessons. In L.

Ortiz-Franco, N. G. Hernandez, \& Y. De la Cruz (Eds.), Changing the faces of mathematics: Perspectives on Latinos (pp. 49-57). Reston, VA: National Council of Teachers of Mathematics.

Holt McDougal. (2011). Mathematics: Grade 7. Boston, MA: Houghton Mifflin Harcourt. Institute of Education Sciences. (2014a). Teaching academic content and literacy to English learners in elementary and middle school. (NCEE 2014-4012). Washington, D.C.: U.S. Department of Education.

Hufferd-Ackles, K., Fuson, K. C., \& Sherin, M. G. (2004). Describing levels and components of a math-talk learning community. Journal for research in Mathematics Education, 35(2) 81116.

Institute of Education Sciences. (2014). Building teacher capacity to support English language learners in schools receiving school improvement grants. (NCEE 2015-4004). Washington, D.C.: U.S. Department of Education.

Janzen, J. (2008). Teaching English language learners in the content areas. Review of Educational Research, 78(4), 1010-1038. 
Kayi-Aydar, H. (2015). Teacher agency, positioning, and English language learners: Voices of preservice classroom teachers. Teaching and Teacher Education, 45, 94-103.

Khisty, L., \& Chval. K. (2002). Pedagogic discourse and equity in mathematics: When teachers' talk matters. Mathematics Education Research Journal 14(3), 154-168.

Khisty, L. L. \& Viego, G. (1999). Challenging conventional wisdom: A case study. In L. OrtizFranco, N. Hernandez, \& Y. De La Cruz (Eds.), Changing the faces of mathematics: perspectives on Latinos (pp. 71-80). Reston, VA: National Council of Teachers of Mathematics.

Lager, C. A. (2006). Types of mathematics-language reading interactions that unnecessarily hinder algebra learning and assessment. Reading Psychology, 27(2-3), 165-204.

Lampert, M. (1985). How do teachers manage to teach? Perspectives on problems in practice. Harvard Educational Review, 55(2), 178-195.

Lemke, J. L. (2003). Mathematics in the middle: Measure, picture, gesture, sign, and word. In M. Anderson, A. Sáenz-Ludlow, S. Zellweger, \& V. V. Cifarelli (Eds.), Educational perspectives on mathematics as semiosis: From thinking to interpreting to knowing (pp. 215-234). Brooklyn, NY: Legas.

Lesaux, N., Kieffer, M., Kelley, J. G., Harris, J. R., (2014). Effects of academic vocabulary instruction for linguistically diverse adolescents: Results from a randomized controlled trial. American Educational Research Journal, 51(6), 1159-1194.

Long, J. S., McKenzie-Robblee, S., Schaefer, L., Steeves, P., Wnuk, S., Pinnegar, E., \& Clandinin, D. J. (2012). Literature review on induction and mentoring related to early career teacher attrition and retention. Mentoring \& Tutoring: Partnership in Learning, 20(1), 7-26. 
Martinello M. \& Wolf, M. K. (2012). Exploring ELLs' understanding of word problems in mathematics assessments: The role of text complexity and student background knowledge. In S. Celedón-Pattichis and N. Ramirez (Eds.) Beyond good teaching: Advancing Mathematics Education for ELLs (pp. 151-162). Reston, VA: National Council of Teachers of Mathematics.

Mestre, J. (1988). The role of language comprehension in mathematics and problem solving. In R. Cocking \& J. Mestre (Eds.), Linguistic and cultural influences on learning mathematics (pp. 201-220). Hillsdale, NJ: Lawrence Erlbaum Associates, Inc.

Miles, M. B., Huberman, A. M., \& Saldaña, J. (2014). Qualitative data analysis: A methods sourcebook. Thousand Oaks, CA: Sage Publications.

Miller, D. L. (1993). Making the connection with language. Arithmetic Teacher, 40(6), 311-317.

Moschkovich, J. N. (1999). Supporting the participation of English language learners in mathematical discussions. For the Learning of Mathematics, 19(1), 11-19.

Moschkovich, J. N. (2002). A Situated and Sociocultural Perspective on Bilingual Mathematics Learners. Mathematical Thinking and Learning, 4(2-3), 189-212.

Moschkovich, J. (2012). Mathematics, the Common Core, and language: Recommendations for mathematics instruction for ELs aligned with the Common Core. Understanding language: Commissioned papers on language and literacy issues in the Common Core State Standards and Next Generation Science Standards, 17-31. Retrieved from http://ell.stanford.edu/sites/default/files/pdf/academic-papers/02JMoschkovich\%20Math\%20FINAL_bound\%20with\%20appendix.pdf 
Moschkovich, J. N. (2015). Academic literacy in mathematics for English learners. The Journal of Mathematical Behavior, 40, 43-62.

National Center for Education Statistics. (2014). The condition of education. Retrieved from https://nces.ed.gov/pubs2014/2014083.pdf

National Council of Teachers of Mathematics. (2010; 2014). Principles and Standards for School Mathematics. Reston, VA: Authors.

National Governors Association Center for Best Practices \& Council of Chief State School Officers. (2010; 2014). Common Core State Standards for Mathematics. Washington, DC: Authors.

O’Halloran, K. L. (2003). Educational implications of mathematics as a multisemiotic discourse. In M. Anderson, A. Saenz-Ludlow, S. Zellweger, \& V. V. Cifarelli (Eds.), Educational perspectives on mathematics as semiosis: From thinking to interpreting to knowing (pp. 185-214). Brooklyn, NY: Legas.

Parveva, T., Noorani, S., Ranguelov, S., Motiejunaite, A., \& Kerpanova, V. (2011). Mathematics education in Europe: Common challenges and national policies. Brussels, Belgium: Education, Audiovisual and Culture Executive Agency, European Commission.

Planas, N. (2014). One speaker, two languages: Learning opportunities in the mathematics classroom. Educational Studies in Mathematics, 87(1), 1-16.

Purpura, D. J., \& Ganley, C. M. (2014). Working memory and language: Skill-specific or domaingeneral relations to mathematics? Journal of Experimental Child Psychology, 122, 104-121. 
Ross, K. E. (2014). Professional development for practicing mathematics teachers: A critical connection to English language learner students in mainstream USA classrooms. Journal of Mathematics Teacher Education, 17(1), 85-100.

Rubenstein, R. N. (1996). Strategies to support the learning of the language of mathematics. In P. C. Elliott \& M. J. Kenney (Eds.), Communication in mathematics: $K-12$ and beyond yearbook (pp. 214-218). Reston, VA: National Council of Teachers of Mathematics.

Saldaña, J. (2013). The coding manual for qualitative researchers. Los Angeles, CA: Sage Publications.

Santos, M., Darling-Hammond, L., \& Cheuk, T. (2012). Teacher development to support English language learners in the context of common core state standards. In Understanding Language Conference, Stanford University, California. Retrieved from http://ell. stanford. edu/sites/default/files/pdf/academic-papers/10-Santos\% 20LDH\% 20Teacher\% 20Development\% 20FINAL. pdf.

Schleppegrell, M. J. (2007). The linguistic challenges of mathematics teaching and learning: A research review. Reading \& Writing Quarterly, 23(2), 139-159.

Secada, W. G., \& De La Cruz, Y. 1996. Teaching mathematics for understanding to bilingual students. In J. Flores (Ed.), Children of la Frontera (pp. 285-308). Charleston, WV: ERIC Clearinghouse on Rural Education and Small Schools.

Setati, M. (1998). Code-switching and mathematical meaning in a senior primary class of second language learners. For the Learning of Mathematics, 18(1), 34-40. 
Setati, M. (2005). Teaching mathematics in a primary multilingual classroom. Journal for Research in Mathematics Education, 36(5), 447-466.

Setati, M. (2012). Mathematics in multilingual classrooms in South Africa: From understanding the problem to exploring possible solutions. In B. Herbel-Eisenmanm, J. Choppin, D. Wagner, \& D. Pimm (Eds.), Equity in discourse for mathematics education: Theories, practices and policies (pp. 125-145). Dordrecht, The Netherlands: Springer.

Spanos, G., Rhodes, N. C., Dale, T. C., \& Crandall, J. (1988). Linguistic features of mathematical problem solving: Insights and applications. In R. Cocking \& J. Mestre (Eds.), Linguistic and cultural influences on learning mathematics (pp. 221-240). Hillsdale, NJ: Lawrence Erlbaum Associates, Inc.

Stake, R. E. (1995). The art of case study research. Los Angeles, CA: Sage Publications.

Stake, R. E. (2006, 2013). Multiple case study analysis. New York, NY: Guilford Press.

Tan, M. (2011). Mathematics and science teachers' beliefs and practices regarding the teaching of language in content learning. Language Teaching Research, 15(3), 325-342.

TERC. (2008). Investigations in number, data, and space (2nd ed.). Glenview, IL: Pearson

Turner, E., Dominguez, H., Maldonado, L., Empson, S. (2013a). English Language Learners identity-enhancing participation in mathematical discussion [Special Issue]. Journal for Research in Mathematics Education, 44(1), 199-234.

Turner, E., Dominguez, H. Empson, S., Maldonado, L. (2013b). Latino/a bilinguals and their teachers developing a shared communicative space. Educational Studies in Mathematics, 84(3), 349-370. 
Turner, E. E., Drake, C., McDuffie, A. R., Aguirre, J., Bartell, T. G., \& Foote, M. Q. (2012). Promoting equity in mathematics teacher preparation: A framework for advancing teacher learning of children's multiple mathematics knowledge bases. Journal of Mathematics Teacher Education, 15(1), 67-82.

Yin, R. K. (2013). Case study research: Design and methods. Los Angeles, CA: Sage Publications. 